\title{
ОБРАЗОВАНИЕ \\ О.Б. Ховов \\ Социальное пространство и социальная действительность системы непрерывного образования
}

\begin{abstract}
Аннотация. Начальная фаза постиндустриализма породила «пространственное» осмысление гуманитарными науками проблем глобализации, в числе которых оказалась проблема социализации индивида. Отечественная педагогика и философия до последнего времени рассматривали соииализацию как включение индивида в систему общественных отношений, как «освоение соииально-культурного опыта - трудовых навыков и т.д.», тогда как на Западе психология и социология исторически исследовали соииализацию как отношения между индивидами в различных жизненных условиях. Именно эта проблема определила предмет исследования автора данной статьи: социальное пространство системы непрерывного образования, рассматриваемое в рамках изменения педагогических, философских и социологических представлений. Автором проводится анализ историко-философской, научно-педагогической, соииологической и культурологической литературы; осуществляется теоретическое моделирование с использованием модели метафизических процессов деятельности.

Новизну исследования составляет разработка трехкомпонентной модели соицального пространства системы непрерывного образования. Предложена концептуальная модель учебной социальной деятельности учащегося, что позволяет перейти от внепредметной воспитательной техники поотрения и наказания $\kappa$ предметной познавательной деятельности, ориентированной на формирование реальных соииальных отношений, социального выбора и социального поведения в целом с учётом силового влияния социального пространства.
\end{abstract}

Ключевые слова: социальное пространство, образовательное пространство, метабизические процессы деятельности, установление связи, структуризация, систематизация, модель учебной социальной деятельности, отношение, выбор, ответственность.

1. 0 взаимосвязи образовательного и социального пространства системе непрерывного образования.

В начале 90-х гг. ХХ в. чиновники Европейского Союза, обсуждая будущую структуру системы образования, общую для всех стран, входящих в ЕС, использовали в качестве метафоры понятие «образовательное пространство». В дальнейшем, представители ЮНЕСКО стали достаточно часто употреблять в докладах ежегодных Международных конференций этот новый термин, придавая ему различные смыслы. В российской педагогике «образовательное пространство» стало обрастать еще большим разнообразием значений, зачастую дублируя существующие педагогические понятия.

Какие же взаимосвязанные объекты наполняют, например, «Европейское образовательное пространство»? Оно включает документы, регламентирующие основные принципы построения децентрализованной образовательной системы; документы, фиксирующие организационно-педагогические условия ее функционирования; юридические и законодательные нормы; стандарты, определяющие структуру педагогической деятельности, структурное единообразие учебных программ и соответствие образовательных уровней. Это комплекс организационных документов «Европейской системы образования», а не образовательное пространство, в котором, на мой взгляд, мысленно взаимодействуют объекты и субъекты собственно образовательной деятельности, осуществляемой учащимся.

Можно бесконечно говорить о развитии образовательного пространства системы непрерывно- 


\section{Образование}

го образования, имея в виду возникновение новых форм образовательных учреждений, увеличение их количества; появление новых образовательных программ и т.д. Но это практически ничего не дает для педагогики как науки о развитии способностей человека (физических, интеллектуальных и нравственных). Поэтому следует перевести этот дискурс на уровень субъектов образовательной деятельности.

Несмотря на Закон Российской Федерации «Об образовании», в котором понятие «образование» фактически определяется как основная функция педагога (обучение и воспитание), в действительности преподаватель только помогает учащемуся создать образовательное пространство, в котором взаимодействуют изучаемые объекты, выявить взаимосвязи этих объектов, определить причины и следствия изменения этих взаимосвязей и т.д. Именно в этом заключается образовательная миссия педагога. Ярким примером такой педагогической формы является майевтика Сократа. Социальная сторона педагогической деятельности заключается в установлении отношений доброжелательного, инициативного взаимодействия.

Таким образом, образовательное пространство - это пространство интеллектуальной деятельности учащегося. Поэтому специально спроектированное здание для организации образовательной деятельности являет собой всего лишь оптимально созданную материальную конструкцию, которая обеспечивает наиболее благоприятные условия для организации образовательного процесса, обеспечения нормальной жизнедеятельности учащихся, их физиологии и здоровья, но само по себе не является образовательным пространством, тем более в отсутствии учащихся. Так же как концертный зал - это не музыкальное пространство. Только оркестр создает гармонию звуков в пространстве, независимо от того, где это происходит - на площади, в парке или в концертном зале.

Решение другой образовательной задачи в рамках целостного образовательного процесса может рассматриваться как смена полей в одном и том же образовательном пространстве.

В некоторых публикациях фигурирует определение понятия «образовательное пространство», которое имеет дублирующее значение, присущее давно установленным педагогическим понятиям (например, образовательное пространство, рас- сматриваемое как институциональные учреждения подсистем образования). В зависимости от контекста это понятие может восприниматься как дошкольное образовательное пространство - детские сады и другие формы институциональных учреждений для дошкольников; детская площадка; игровая комната; стол, на котором находится альбом для рисования с карандашами, стульчик и т.д.

Появляются еще более непродуманные формулировки, например, «образовательное пространство - совокупность образовательныхучреждений разного типа и взаимодействующих с ними общественных и государственных организаций...». Спрашивается, при чём здесь образовательное пространство, когда речь идет, в основном, об информационном взаимодействии чиновников системы образования (руководство школы, аппарат министерства образования).

Таким образом, главная причина многообразия определений образовательного пространства коренится в многозначности термина «образование»!

С семантической точки зрения понятие «образовательное пространство» может рассматриваться как сигнификат, т.е. как термин, означающий нечто, но который необязательно должен употребляться как денотат, т.е. необязательно ему должно соответствовать конкретное значение.

Если мы хотим рассматривать исследуемое понятие как денотат, т.е. как действительно научное понятие, независимо от контекста, то первоначально необходимо выявить его сущность, которая, на мой взгляд, заключается в создании учащимся мысленной конструкции взаимосвязей объектов познавательной деятельности. То, что обыденно педагоги называют процессом ничего не говорящего «учения». Представляется, что исходным моментом в определении образовательного пространства может служить понятие «процесса мыследействия», по терминологии Г.П. Щедровицкого.

При таком онтологическом подходе, когда выявляется сущность явления или процесса, может быть сформулировано следующее определение:

образовательное пространство может быть представлено одним из трёх видов пространств - мысленно формируемое (например, пространство профессиональной деятельности), виртуальное (кино, видео, телевизионное, ин- 


\section{Педагогика и просвещение 4(16) • 2014}

тернет) и реальное физическое пространство, в которых учащийся в процессе познавательной деятельности мысленно устанавливает определенные взаимосвязи, отношения между объектами (субъектами), с целью формирования знаний порождения новых способностей, образов, структур, моделей, ценностей и освоения технологий в материальной, интеллектуальной или нравственной сферах.

Итак, мы приходим к выводу о том, что образовательное пространство не может предстать одновременно и как социальное пространство. Остаётся выяснить ещё один вопрос: может ли социальное пространство предстать в качестве образовательного? Безусловно, да. В этом случае учащийся включается в мысленную или реальную конструкцию отношений с другими субъектами. Педагогические исследования по этой проблематике в западных странах (Великобритания, Франция, Германия, США) ведутся начиная с 60-х годов прошлого столетия. Разработаны и внедрены учебные программы социального развития учащихся [1]. Российской педагогике только предстоит осознать всю важность подобной работы.

При таком многозначном восприятии образовательного и социального пространств их исследование должно базироваться на принципе релятивизма, который заключается в выборе исследователем совершенно определённой позиции. Напомним, что «релятивизм (от лат. relativus относительный) - 1) то же самое, что реляционализм; 2) философская, гносеологическая точка зрения, впервые отчетливо представленная софистом Горгием, согласно которой все знания рассматриваются лишь как относительно правильные, ибо они обусловливаются положением, которое в зависимости от обстоятельств занимает познающий. В философии культуры и философии истории релятивизм исповедуется довольно часто...» [2].

\section{2. Истоки возникновения многомерности} характеристик социального пространства

Проблема социального пространства находит свое отражение в таких областях науки как социальная философия, социальная педагогика, социальная психология и социология. Так социальная философия касается идеи социального пространства при рассмотрении вопросов развивающегося во времени общества, деятельности субъектов истории, социальных процессов и феноменов в их взаимосвязи. В социальной психологии проблема социального пространства возникает в рамках теоретической структуризации гипотетического явления, определяемого как «отношение к другому субъекту». В таком контексте понятие отношение определяется как предрасположенность к классификации ситуаций наблюдения действий или взаимодействия с "другим субъектом» и реакции на них с определённой степенью постоянства в оценках. Другие исследователи представляют социальное пространство как внутреннее "поле", как степень свободы деятельности личности, группы.

Социологическая наука рассматривает социальное пространство также с нескольких точек зрения:

- социальное пространство как социально освоенная часть природного пространства, как среда обитания людей (пространственнотерриториальный аспект жизнедеятельности общества и предметного мира человека);

- социальное пространство как характеристика социальной структуры общества с точки зрения "расположения" социальных групп и слоев в “пространстве" условий, возможностей их развития.

Специальными социологическими дисциплинами являются: социология права, социология культуры, социология искусства, социология литературы, социология хозяйства и производства, социология техники, социология труда, социология финансов, педагогическая социология, социология знания и т.д.

В сфере социологии значительный интерес представляют работы П. Бурдьё, в которых социальное пространство исследуется как объективное явление с позиций генетического структурализма. Другие направления социологических исследований социального пространства касаются экономических, политических, профессиональных и пр. аспектов взаимодействия коллективов и сообществ.

Отечественная социальная педагогика, исследуя проблемы социального воспитания, до последнего времени рассматривала влияние социальной среды на социализацию учащегося (страна, регион, этнос, общество, государство, тип поселения, средства массовой коммуникации, семья, соседство доминантная социальная группа, конфессиональное воспитание и т.п. (А.В. Мудрик, 


\section{Образование}

В.А. Сластёнин). Советская философия определяла социализацию как «процесс освоения ... социальнокультурного опыта - трудовых навыков, знаний, норм, ценностей, традиций...». В данном случае социальное пространство предстаёт в конкретной форме среды. Подобный подход представляет собой некий конгломерат социологических, социально психологических и социально-философских направлений исследований применительно к воспитательной функции образования.

Таким образом, наука исследует социальное пространство, представленное, по крайней мере, в четырёх формах - абстрактной, конкретной, объективной и субъективной.

Многообразие исследовательских направлений порождает соответствующие понятийнотерминологические аппараты, вследствие чего возникает многомерность характеристик социального пространства. Поэтому исследование вопросов развития социального пространства системы непрерывного образования предполагает выбор релятивистской позиции, которая, на мой взгляд, определяется концептуально и методологически. Концептуально - в центре данной проблемы педагогического исследования должен быть развивающийся человек, а не взаимосвязь социальных сообществ или образовательных организаций. Методологически - исследование должно принимать во внимание, но не обязательно опираться на наиболее продвинутые идеи, признанные профессиональным сообществом. В данном случае, это исследования французского социолога Пьера Бурдьё, относящиеся ко второй половине прошлого столетия.

\section{3. «Социальное пространство» в работах П. Бурдьё}

В основе формирования научных воззрений П. Бурдьё на социальное пространство как на некоторую структуру социальных позиций, под которыми исследователь понимает сами элементы социального пространства, лежит релятивистская концепция пространства, предложенная в конце XVII в. Г. Лейбницем. Смысл этой концепции заключается в том, что «каждая монада (вещь сама по себе - O.X.) воспринимает мир в своей, лишь ей присущей перспективе, и в этом смысле можно говорить о пространственном положении монад. Таким образом, пространство, по Лейбницу, есть свойство вещей самих по себе. Реляционная трак- товка пространства, определяемого в каждый момент конфигурацией сил, сводит его к порядку возможного сосуществования монад. Для реляционизма пространство служит общей формой координации объектов и их состояний, откуда следует зависимость свойств пространства от характера взаимодействия объектов» [3].

Я выделил часть цитаты, с тем, чтобы обратить внимание на «силовую» характеристику пространства, установленную еще Лейбницем, которая оказалась важной не только для исследований П. Бурдьё, но и для нашего исследования социального пространства системы непрерывного образования.

Главным свойством социального отношения, утверждает П. Бурдьё, является то, что оно выступает как «сила», как необходимое, активирующее условие, предпосылка непосредственных взаимодействий, представлений или практик (реальных действий $-O . X$.) индивидуальных и коллективных агентов. С другой стороны, сила представлена как свойство социальной структуры. Именно силы учреждают социальное пространство, поэтому оно не является пассивным вместилищем его элементов, а активно изменяется, движется.

Таким образом, структура позиций рассматривается как структура «источников»силы. Структура социального пространства формально становится проявлением социальных структур, существующих в действительности.

В генетическом структурализме - научном направлении начала XX в., в рамках которого П. Бурдьё выстраивает свои модели, основная функция поля заключается в изменении состояния социального пространства. «Поле» определяется как вторичное понятие, тогда как первичным является «сила».

Социальные процессы рассматриваются как изменения состояния социального пространства, происходящие под действием сил.

Принимая во внимание представленные выше характеристики компонентов социального пространства, фигурирующие в работах П. Бурдьё, следует критически отнестись к определению социального пространства, предложенному в «Википедии»:

- Социальное пространство - один из видов пространства (наряду с физическим и другими); многомерное пространство социальных процессов, социальных отношений, социальных 


\section{Педагогика и просвещение 4(16) • 2014}

практик, социальных позиций и социальных полей...

В этом определении, основанном на понятийно-терминологическом аппарате П. Бурдьё, совершенно не представлена силовая характеристика социального пространства, как наиболее значимая в исследованиях автора, не показаны гипотетичность, движение и изменчивость социального пространства. Это один из множества примеров, который показывает, что для педагогических исследований нельзя использовать определения «Википедии» в качестве догматов или ссылок, что иногда встречается в публикациях.

\section{4. Методологическая база исследования социального пространства системы непрерыв- ного образования}

Смысл многочисленных работ П. Бурдьё по формализации, созданию некоей модели неосязаемого, по сути, гипотетически существующего «социального пространства», заключается в том, чтобы на вполне научной базе построитьновый подход к исследованию социальной действительности.

Выявив основные компоненты, силовую природу и взаимосвязанные характеристики социального пространства, исследователь приходит к выводу о двойном структурировании социальной действительности.

Н.А. Шматко в своём послесловии к сборнику статей П. Бурдьё пишет: «Говоря об активной роли (социальных - O.X.) агентов в воспроизводстве/производстве социальной действительности, Бурдьё подчеркивает, что оно невозможно без инкорпорированных структур - практических схем, являющихся продуктом интериоризации (социальными агентами - O.X.) объективных социальных структур. Отсюда следует, что субъективное структурирование социальной действительности есть подчинённый момент структурирования объективного» [3].

Напомним один из выводов П. Бурдьё: «силу» или «силовые отношения» надо понимать как объективную социальную структуру, а «смысловые отношения» принадлежат региону субъективных социальных явлений.

П. Бурдьё делает следующий вывод : «Социальная действительность, то есть то, что существует до и помимо науки, может быть представлена с помощью бесчисленного множества социальных пространств, различающихся своим объемом (совокупностью выражаемых в них явлений) и структурой.

Создавая методологическую базу для нашего исследования, кроме выводов П. Бурдьё, о силовой природе социального пространства, мы используем современные представления о духовном мире человека и основные положения общей теории деятельности, предложенной автором данной статьи в 2004 г. [4, 5, 6].

Эта теория дала ответ на вопрос о том, почему человеческая деятельность, представленная в различных формах и в различных областях науки и практики в результате генерализации чаще всего репрезентируется в виде триад (трёх последовательных процессов).

Например: созерцание, теория, «праксис» (древнегреческая философия); приобретение знаний, порождение умений, формирование навыков; обучение, развитие, воспитание (П.Ф. Каптерев, Л.С. Выготский); интеллектуальная, аффективная и психомоторная деятельность (Б. Блум); проектирование, конструирование, технологическая подготовка (разработка промышленных изделий); установление связи между нейронами, изменение структуры мозга (возникновение «ансамбля»), целостное воспроизведение «ансамбля» (механизм памяти, нейрология).

Подобных примеров зафиксировано более 20. Выявление общих свойств соответственно начальных, промежуточных и заключительных процессов показало, что метафизический (сущностный) смысл этих процессов заключен в следующей триаде: установление связи, структуризация, систематизация.

Собственный опыт участия в процессах проектирования, конструирования, технологических разработок для производства армейских транспортных средств подсказывал, что каждый из трех последовательных процессов определенным образом участвует в двух других.

Теоретическое подтверждение этой идеи было обнаружено при рассмотрении принципа полного взаимодействия субстанций И. Канта, который использовали А.В. Петровский и М.Г. Ярошевский для построения дуальной категориальной системы теоретической психологии [7, с. 13]. Смысл этого принципа заключен в следующем - каждая из одноуровневых категорий содержит в себе «отпечатки» других категорий того же уровня. На основании данного принципа И. Канта была построена 


\section{Образование}

модель метафизических процессов деятельности, которая продемонстрировала, что результат достигается выполнением трех последовательных процессов (установление связи, структуризация, систематизация), каждый из которых состоит из трёх соответствующих операций.

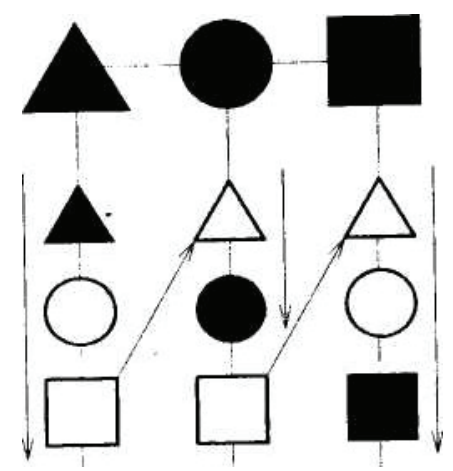

Рис. 1. Модель метафизических (сущностных) процессов деятельности.

В теории самоорганизации (синергетика) движение от хаоса к упорядоченности характеризуется неравновесностью. Наша модель также отражает данный принцип - неравновесность силового воздействия процессов деятельности. Верификация показала, что выводы, содержащиеся в исследованиях процессов деятельности Б. Блум, Л.С. Выготский, П.Я. Гальперин, И.С. Гербарт, В.В. Давыдов, П.Ф. Каптерев, А.Н. Леонтьев, А.В. Петровский, К.К. Платонов, Р. Стернберг) достаточно точно корреспондируются с предложенной моделью, используемой в качестве «матрицы», которая в отдельных случаях уточняла эмпирические выводы ученых.

В отличие от рационализма Р. Декарта, основанного на противопоставлении (противоречии) «протяженной» (материальной) субстанции, определяемой априорными причинно-следственными отношениями, и «мыслящей» (духовной) субстанции, определяемой телеологическими (целеполагающими отношениями, использованной И. Кантом, Г. Гегелем, К. Марксом и частью неокантианцев), с начала XX в. философия Запада, на мой взгляд, возвращается к метафизической, но современной трактовке непротиворечивого в своей взаимосвязанности бытия.

Новое понимание духа, человеческой духовности существенно отличается от определений, предлагаемых в советских энциклопедиях.
«... Дух выступает трех формах бытия: как дух отдельного индивида (личный дух), как общий дух (объективный дух) и как объективированный дух (совокупность завершенных творений духа).

Личный дух становится самим собой благодаря врастанию индивида в область объективного духа, в духовную сферу, культуру, которую он находит и которую может (частично) усвоить с помощью воспитания и образования. Объективный дух связан с личным духом посредством истории духовной жизни человека с объективированным духом - посредством истории духа» [1].

\section{5. Социальное пространство и социальная действительность системы непрерывного} образования

На основании созданной методологической базы оказывается возможным рассмотреть модель реальной ситуации социальной действительности на уроке в каком-нибудь 7 «Б» классе средней школы, зафиксировав силовое воздействие на учащихся (коллективный агент) трёх полей социального пространства - поле, создаваемое фактором субъективного авторитета преподавателя; поле, создаваемое требованиями, распорядком и правилами объективной структуры школы; поле, создаваемое социально-правовыми нормами Конституции, социально-значимыми законами, общественно признанными ценностями и нормами морали представляющими собой воздействие объективированного социального пространства.

Безусловно, на социальные действия отдельного учащегося в реальности дополнительное влияние оказывают социальное пространства: семейного уклада, доминантной группы сверстников, определенной молодежной субкультуры и т.д., - которые наша модель не учитывает.

Данная модель социального пространства сопровождает человека на протяжении всей жизни. Силовое влияние на социальные действия взрослого человека всегда определяется (или должно определяться) компонентами объективизированного социального пространства, которые на протяжении жизни являются практически константами, тогда как другие поля подвижны.

Декларирование социальных норм и ценностей, осуществляемое в рамках воспитательной практики с целью их усвоения и принятия учащимися, давно не работает, поскольку этот процесс 


\section{Педагогика и просвещение 4(16) • 2014}

даже не систематизирован и не возведен в ранг многоразового ежедневного ритуала «поучения», который существует в конфессиональных структурах почти 2000 лет.

Необходим фундаментально разработанный путь поэтапного движения к пониманию и принятию социальных норм и ценностей, в отечественной школе до настоящего времени не существует систематизированной предметной педагогической деятельности по созданию социально ориентированных учебных ситуаций для самостоятельного разрешения и рефлексии.

Как интериоризированные источники силы компоненты социального пространства оказывают существенно важное влияние на инициативные или реактивные социально значимые действия учащегося, которые формируются следующим образом: «отношение» - «выбор» - «ответственность».

Таким представляется один из путей движения к социальному действию, к социальной норме и ценностям.

Как указывалось выше, социальное отношение - это гипотетическая конструкция ненаблюдаемой психологической связи с другим субъектом или группой. Оно формируется заинтересованным восприятием другого: реакцией органов чувств, обращением внимания на качество мышления, стиль поведения и т.д. Сознательный или бессознательный выбор жестов, вербальных коммуникаций степени доверия; Определенность и постоянство внутренней социальной позиции. Осознанный выбор модели социального поведения представляет собой конструирование последовательности действий и осмысление возможных последствий сделанного выбора.

Процесс реализации выбранного решения, по сути принятие ответственности, требует освоения специфических способностей: привычная активизация, как способность быть наготове в типовой ситуации, подготовленность к автоматизированному действию, без усилий на сознательном уровне; опыт вполне сформированных технологий принятия решений; проявление инициативы; готовность принятия ответственности за принятое решение; способность принятия рациональных решений в критической ситуации.

Подобный подход, реализуемый в рамках предметного преподавания, безусловно повысит в определенный момент преподавательскую нагрузку, но, в то же время, позволит активнее включить самостоятельное обучение, а точнее самостоятельное НАУЧЕНИЕ, уделяя больше внимания индивидуальным консультациям и индивидуальному контролю.

Таким образом, систематическое овладение учащимися и студентами, дифференцированными по уровням системы непрерывного образования конкретными социально значимыми действиями (отношение, выбор, принятие социальной и гражданской ответственности) в условиях ясно осознаваемых силовых воздействий многомерных социальных пространств может стать весьма важным компонентом в образовательной практике школы, что позволит выпускникам более эффективно адаптироваться к миру глобального взаимодействия.

\section{Список литературы:}

1. Попова М.В. Как преподают психологию на Западе // Педагогика. 1998. № 3.

2. Философский энциклопедический словарь. М., 2001.

3. «Социальное пространство» Пьера Бурдьё. Послесловие Н.А. Шматко // Бурдье П. Социальное пространство: поля и практики: Сб. статей / Сост., общ. ред. пер. и послесл. Н.А. Шматко. М.: Ин-т эксперим. социологии; СПб.: АЛЕТЕЙЯ, 2005.

4. Ховов О.Б. Теория деятельности. М.: Изд-во РАО, 2004.

5. Х Ховов О.Б. Исторические циклы культурно-образовательных парадигм // Вестник Ленинградского государственного университета имени А.С. Пушкина. 2009. № 1. С. 57-84.

6. Ховов О.Б. Наука о системном совершенствовании человеческой деятельности // Материалы 11-й Международной конференции «Образование через всю жизнь: непрерывное образование в ин- 


\section{Образование}

тересах устойчивого развития». Вып. 11. Часть 1. СПб., 2013. С. 93-96. (http://lifelong-education. ru/images/pdf/2013_ru_1.pdf).

7. Петровский А.В., Ярошевский М.Г. Теоретическая психология. М.: Академия, 2001.

8. История философии. Запад, Россия, Восток. В 4-х тт. / Под ред. Н.В. Мотрошиловой. М., 1996.

9. Философский словарь / Под ред. И.Т. Фролова. М.: Изд-во политической литературы, 1986.

\section{References (transliteration):}

1. Popova M.V. Kak prepodayut psikhologiyu na Zapade // Pedagogika. 1998. № 3.

2. Filosofskii entsiklopedicheskii slovar'. M., 2001.

3. «Sotsial'noe prostranstvo» P'era Burd'e. Posleslovie N.A. Shmatko // Burd'e P. Sotsial'noe prostranstvo: polya i praktiki: Sb. statei / Sost., obshch. red. per. i poslesl. N.A. Shmatko. M.: In-t eksperim. sotsiologii; SPb.: ALETEIYa, 2005.

4. Khovov O.B. Teoriya deyatel'nosti. M.: Izd-vo RAO, 2004.

5. Khovov O.B. Istoricheskie tsikly kul'turno-obrazovatel'nykh paradigm // Vestnik Leningradskogo gosudarstvennogo universiteta imeni A.S. Pushkina. 2009. № 1. S. 57-84.

6. Khovov O.B. Nauka o sistemnom sovershenstvovanii chelovecheskoi deyatel'nosti // Materialy 11-i Mezhdunarodnoi konferentsii «Obrazovanie cherez vsyu zhizn': nepreryvnoe obrazovanie v interesakh ustoichivogo razvitiya». Vyp. 11. Chast' 1. SPb., 2013. S. 93-96. (http://lifelong-education.ru/images/pdf/2013_ru_1.pdf).

7. Petrovskii A.V., Yaroshevskii M.G. Teoreticheskaya psikhologiya. M.: Akademiya, 2001.

8. Istoriya filosofii. Zapad, Rossiya, Vostok. V 4-kh tt. / Pod red. N.V. Motroshilovoi. M., 1996.

9. Filosofskii slovar' / Pod red. I.T. Frolova. M.: Izd-vo politicheskoi literatury, 1986. 